Published in final edited form as:

Autism. 2011 July ; 15(4): 437-456. doi:10.1177/1362361310386507.

\title{
Phenomenology and measurement of circumscribed interests in autism spectrum disorders
}

\author{
LAUREN M. TURNER - BROWN, \\ Carolina Institute for Developmental Disabilities, University of North Carolina at Chapel Hill, USA
}

KRISTEN S. L. LAM,

Carolina Institute for Developmental Disabilities, University of North Carolina at Chapel Hill, USA

TIA N. HOLTZCLAW, Carolina Institute for Developmental Disabilities, University of North Carolina at Chapel Hill, USA

GABRIEL S. DICHTER, and

Carolina Institute for Developmental Disabilities, University of North Carolina at Chapel Hill, USA

JAMES W. BODFISH

Carolina Institute for Developmental Disabilities, University of North Carolina at Chapel Hill, USA

\section{Abstract}

Circumscribed interests (CI) are important and understudied symptoms that affect individuals with autism spectrum disorders (ASD). The present study sought to develop quantitative measures of the content, intensity and functional impairment of $\mathrm{CI}$ in 50 children with high-functioning ASD compared to an age-, IQ-, and gender-matched sample of 50 typically developing (TD) peers. The Interests Scale, a parent-rating questionnaire, and the Interview for Repetitive Behaviors, a semistructured interview, were used to assess CI. Groups did not differ on the number of interests children held, but they did differ on types of interests and impairment associated with them. The interests of ASD participants were more likely to be nonsocial in nature (e.g. mechanical systems) than TD participants. Parents of children with ASD endorsed higher degrees of functional impairment on metrics including frequency, interference, resistance when interrupted, flexibility, and accommodation required, as well as less involvement of other people, than parents of children with TD. These findings suggest that interests of individuals with ASD differ qualitatively and in intensity from individuals with TD. The present study offers further support for the notion that CI reflect a clinically significant feature of ASD that warrants intervention in some children.

\section{Keywords}

circumscribed interests; repetitive behavior; restricted interests

Circumscribed interests (CI) in autism were originally described by Leo Kanner in his seminal paper in 1943 (Kanner, 1943: 233). One case, Alfred L., was described in the following way:

He has gradually shown a marked tendency toward developing one special interest which will completely dominate his day's activities. He talks of little else while the

(C) 2011 SAGE Publications and The National Autistic Society

ADDRESS Correspondence should be addressed to: LAUREN TURNER BROWN, Carolina Institute for Developmental Disabilities, University of North Carolina at Chapel Hill School of Medicine, CB \#7255, Chapel Hill, NC 27599-7255, USA.

lauren_turner@med.unc.edu. 
interest exists, he frets when he is not able to indulge in it (by seeing it, coming in contact with it, drawing pictures of it), and it is difficult to get his attention because of his preoccupation.

Individuals with autism spectrum disorders (ASD) with and without co-occurring intellectual disability have CI (Baron-Cohen and Wheelwright, 1999; Bartak and Rutter, 1976; Freeman et al., 1981; Kanner, 1943; Lewis and Bodfish, 1998; Ozonoff et al., 2000; South et al., 2005).

In the diagnostic criteria for autism, $\mathrm{CI}$ are listed within the domain of restricted and repetitive behavior (American Psychiatric Association, 2000). This symptom domain in autism includes a range of behaviors including motor stereotypies and adherence to routines and rituals. Recent research has examined this domain of behavior and suggested that these symptoms may not reflect one construct. Research by several groups has found a two-factor model to best describe this symptom domain as measured by the Autism Diagnostic Interview-Revised (ADI-R), with motor stereotypies (e.g. lower-order repetitive behavior) separating from adherence to routines and rituals (e.g. higher-order repetitive behaviour; Cuccaro et al., 2003; Turner, 1999). However, in these studies, items focusing on CI were omitted. When items tapping CI have been included, a three-factor model optimally fits the domain for repetitive behavior, with CI emerging as a unique factor (Lam et al., 2008). Of particular significance in this study were the findings that 88 per cent of children with ASD had CI, that the CI factor alone was not associated with intelligence or severity of other autism symptoms, and that $\mathrm{CI}$ were familial when examining sibling data. A different research group replicated these findings (Smith et al., 2009), finding a factor they labeled 'intense preoccupations'. Their results also found evidence of familiality in that this factor was associated with the broader autism phenotype of rigidity and aloofness in family members. These findings suggest that $\mathrm{CI}$ are prevalent in autism, and their independence from co-occurring autism features and association with familial characteristics indicates that $\mathrm{CI}$ may be associated with unique pathogenic factors.

While interests per se are not indicative of atypical development, the results of previous studies of CI in ASD provide information on the ways that interests in autism may differ from interests seen in the course of typical development. Baron-Cohen and Wheelwright (1999) reported that persons with ASD were more likely to have interests that could be characterized within the knowledge domain of 'folk physics' which involved knowledge about mechanical and nonsocial aspects of the world (e.g. understanding how machines work, vehicles, physical systems) as opposed to the domain of 'folk psychology' which involves knowledge about social aspects of the world (e.g. social relationships, imagination, beliefs). Consistent with this finding, South et al. (2005) reported some common forms of CI that were manifested by persons with ASD including an interest in vehicles, electronics, dinosaurs, particular animals, schedules, or numbers. In a recent study, our research team reported that images representing the types of objects commonly involved in CI elicited a unique pattern of visual attention in children with ASD that was characterized by a more perseverative and circumscribed attentional style relative to non-CI images (Sasson et al., 2008). Further, for children with ASD, but not typically developing children, the presence of $\mathrm{CI}$ images reduced overall visual exploration and especially exploration of social images. This latter finding suggests one way in which CI could be associated with functional impairment in ASD: the presence of strong nonsocial interests could potentially diminish the types of social experiences that are important for experience-dependent brain and behavioral development.

Clinically it is not always clear that CI in individuals with autism represent an area of functional impairment; therefore it is not always known if $\mathrm{CI}$ are a reasonable target for intervention. In a detailed phenomenological study of CI in autism, Mercier et al. (2000) 
reported that at least some persons with ASD and/or their families see CI as an area of unique strength or cognitive skill. Similarly, studies of typically developing children have shown that highly focused, restricted interests occur in some children without ASD, albeit more in boys than in girls (DeLoache et al., 2007). Alternatively, CI may be viewed as associated with impairment for several reasons. Parents report that circumscribed, rigid, and repetitive patterns of behavior are among the most difficult aspect of autism that they face on an everyday basis (Mercier et al., 2000; South et al., 2005). Further, if children with ASD focus on their area of interest to the exclusion of all else, CI may restrict the experiences of children with autism (Pierce and Courchesne, 2001), or interfere with learning and the development of adaptive behavior (Koegel and Covert, 1972; Koegel et al., 1974; Lovaas et al., 1971; Varni et al., 1979). Given the possibility that CI are common in ASD and may be associated with unique pathogenic factors, it is important to develop methods for operationalizing the potential functional impairment of this specific symptom area in ASD.

The goals of the present study were (a) to develop a practical method for measuring CI and their potential functional impairment, and (b) to examine in detail if adolescents with highfunctioning ASD differ from their typically developing peers, either in terms of the content of manifest interests or the degree of functional impairment associated with interests. Based upon previous research, we hypothesized that interests in ASD would differ from interests in children without ASD in four ways. First, the general concept of 'restricted' or 'circumscribed' interests suggests that individuals with ASD have a smaller number of interests than their peers. Second, we hypothesized that the content of interests would differ for individuals with ASD from that of their peers. Third, the clinical description of an interest as being 'circumscribed' sometimes refers to the unusual manner in which a child with ASD focuses on or engages in a particular area of interest (e.g. an interest in detailed train schedules rather than a more broad interest in trains such as that seen in persons with a train 'hobby'). In line with this, we developed an operational definition for 'unusual interest' and hypothesized that persons with ASD would demonstrate more unusual interests than their non-autistic peers. Fourth, we reasoned that functional impairment associated with CI could manifest in multiple ways (e.g. more time spent engaging in the interest, more interference with other activities, becoming distressed when interest is unavailable, or more parental accommodation required to deal with the interest). We hypothesized that interests in ASD are associated with more impairment in these areas than interests in persons without ASD. As existing autism clinical rating scales were not developed to measure circumscribed interests per se or the multidimensional nature of potential functional impairment associated with CI, we developed a set of two instruments to help examine the study hypotheses. The Interests Scale was developed to tap into the range of possible interests all children may have, and the level of involvement they have with these interests. The Interview for Repetitive Behavior was developed to examine more specifically the degree of functional impairment associated with any apparent circumscribed interests.

In the present study we compared children with high-functioning ASDs to an age-, IQ-, and gender-matched contrast group across the multiple dimensions of interests described above (e.g. number, content, atypicality, and functional impairment). Within the ASD sample, we also examined the association between $\mathrm{CI}$ and other symptom domains of autism.

\section{Method}

\section{Participants}

Children with ASD and children with typical development were recruited through a larger study on restricted and repetitive behaviors. Participants with ASD were recruited through the University of North Carolina (UNC) Autism Research Registry in conjunction with regional TEACCH (Treatment and Education of Autistic and related Communication- 
handicapped CHildren) clinics. Inclusion in the registry required a previous clinical diagnosis of ASD made by a licensed clinician experienced in the assessment and diagnosis of ASD, and based on parent interview and direct observation for the completion of one or more standardized autism diagnostic assessment instruments (i.e. Autism Diagnostic Interview-Revised, Social Communication Questionnaire, Autism Diagnostic Observation Schedule, Childhood Autism Rating Scale). Typically developing children (TD) were recruited via a mass email sent to UNC faculty and staff.

Inclusion criteria included: age between 6 and 17 years, inclusive; intelligence quotient (IQ) greater than 70; absence of seizure disorder and acute medical or genetic condition; and absence of any visual impairment uncorrectable with eyeglasses. Parents of all children completed the Social Responsiveness Scale (Constantino and Gruber, 2002). This parental report tool provided a measure of current autism symptoms. Parents of children in the ASD group also completed the ADI-R (Lord et al., 1994) to examine lifetime criteria for ASD. Finally, all children completed the Leiter International Performance Scale-Revised (LeiterR; Roid and Miller, 2002) to ensure IQs were above 70. Based upon performance on these measures, children in the ASD group were excluded if they did not meet both lifetime criteria for autism or ASD on the ADI-R and current criteria for ASD on the Social Responsiveness Scale. Likewise, children in the TD group were excluded if they received a score above the ASD cutoff on the SRS. Children with TD were also excluded if they had a history of any psychiatric or developmental disorder, if they were currently taking psychotropic medication, or if an immediate family member had an ASD diagnosis.

A total of 144 children were recruited to participate, 81 with ASD and 64 with TD. Of 81 potential ASD participants, 21 were excluded from analysis because they did not meet inclusion criteria for this study: 11 had IQ scores below 70, 9 had SRS scores below the ASD cutoff, and 1 was a twin of another participant. One TD child was excluded due to SRS scores above the ASD cutoff.

The resulting sample included 60 children with ASD (autism $n=30$, Asperger syndrome $n=$ 22 , PDDNOS $n=8$ ) and 63 children with TD. See Table 1 for a description of the entire sample. There were no significant differences between groups for ethnicity, $\chi^{2}(2, N=123)$ $=.485$, or sex, $\chi^{2}(2, N=123)=.10, p \mathrm{~s}>.05$. There were significant differences between groups for IQ, $t(121)=4.0, p<.01$ and for chronological age, $(121)=t 2.2, p<.05$, reflecting that children in the TD group scored higher on the Leiter-R and were older than children in the ASD group. Because of these differences, a subsample matched on age and IQ was used in this study for group comparisons only. This matched sample included 50 children in each group. See Table 1 for a description of the matched sample. There were no group differences between matched groups on ethnicity, gender, age or IQ, $p \mathrm{~s}>$.3. For analysis with the ASD group only and for examination of psychometric properties, the complete sample was used.

Prior to participation all individuals and their legal guardians supplied written informed assent and consent for participation in this study. The protocol for this study was approved by the UNC-Chapel Hill School of Medicine Biomedical Institutional Review Board.

\section{Measures}

The Interests Scale-The Interests Scale (Bodfish, 2003), developed for this study, contains a checklist of 39 items that describe typical childhood interests. Parents rated whether their child spends time with or focuses on each item. Parents also responded to an open-ended question to identify their child's primary interest or hobby, and answered seven questions about any functional impairment associated with that interest. These multiple choice questions asked parents to rate their child's overall interest, the frequency of activity 
related to the interest, the degree of interference with other activities, the degree of resistance when interrupted, the degree of flexibility or adaptability, the amount of accommodation required, and involvement of others. The overall interest question was rated on a 1-3 scale; all others were rated on a 0-3 scale with higher scores reflecting more functional impairment. A total impairment score is calculated that is a summary score of the flexibility, frequency, intensity, interference, accommodation, and inclusion of others related to that interest (range 0-22; higher score indicates greater severity and isolation). Variables include a) the number of everyday interests or hobbies children have, and b) the impairment ratings associated with their primary interest. Parents of children in both groups completed the Interests Scale.

The Interview for Repetitive Behavior-The Interview for Repetitive Behaviors (Bodfish, 2003) is a structured clinical interview used to confirm participant-specific forms of repetitive behavior endorsed on the Repetitive Behavior Scales-Revised (Bodfishet al., 1999; Lam and Aman, 2007). A severity score is assigned to each subject-specific form of repetitive behavior ( $0-15$; higher score indicates greater severity). The set of interview questions targeting circumscribed interests (IRB-CI) was used for the present study. These questions probe parents to describe in detail their child's CI and the functional impairment associated with the CI. Specifically, parents are asked to report how often the behavior occurs (frequency; rated 0-5), whether the child becomes distressed when the behavior is blocked (intensity; rated 0-4), whether the behavior causes problems at the child's school or during home activities (interference, rated 0-3), and how often they provide items for the child's behavior to take place or participate in the behavior (accommodation, rated 0-4). Higher scores are associated with more functional impairment. This interview was completed only with parents of children in the ASD group.

Repetitive Behavior Scale-Revised-The RBS-R (Bodfish et al., 1999; Lam and Aman, 2007) is an informant-based questionnaire that assesses 43 discrete types of repetitive behavior within 5 categories (motor stereo-typy, repetitive self-injury, compulsions, routines/sameness, restricted interests). Recent studies (Lam and Aman, 2007; Lam et al., 2005) suggest that the RBS-R is a reliable and valid measure of repetitive behaviors in ASD (internal consistency: alpha ranging between $0.78-0.91$, test-retest reliability $0.52-0.89$, inter-rater reliability $0.55-0.78$, and good convergent and discriminant validity). The RBS-R was used to determine the presence of specific repetitive behaviors and their overall severity for children in both groups.

The Autism Diagnostic Interview-Revised-The ADI-R (Lord et al., 1994) is a comprehensive interview completed with parents to assess autism symptoms in core domains. The ADI-R was used in the present study to confirm diagnoses of participants and as a measure of symptom severity in social, communication, and repetitive behavior domains.

\section{Results}

\section{Psychometric properties of the Interests Scale and the Interview for Repetitive Behavior}

Internal consistency reliability was examined for both the IS and the IRB-CI. The IS includes 7 items tapping the impairment of children's primary interest area. The IS was completed by parents of children in both groups. There was missing data for 3 cases. Internal consistency was calculated for the remaining 120 children. Results revealed strong internal consistency, with a Cronbach's alpha of .81 for all 7 impairment items. 
The IRB-CI was completed by parents of children in the ASD group only, with 3 missing cases $(n=57)$. Scores reflected 4 items tapping the impairment of a child's circumscribed interest (frequency, intensity, interference, and accommodation). Results revealed an alpha of .59 , suggesting these items may not reflect one construct.

\section{Group differences on the Interests Scale}

Number of interests-The total number of current interests from the IS was used for these analyses. Group differences were examined using independent sample $t$ tests. Means and standard deviations for each variable are presented in Table 2. Parents in both groups endorsed an average of about 12 'current interests.' Results revealed no significant group differences, $t(98)=.02, p=.99$.

Content of interests-Baron-Cohen and Wheelwright (1999) found that children with ASD showed more interests within the domain of folk physics, and fewer interests within folk psychology than children with Tourette's syndrome. Thus, we created subcategories from the IS that measure folk physics ( 7 items: machines, mechanical systems, vehicles, building, computers, physics, object motions) and folk psychology (5 items: people, religion, politics, social games, and psychology) using the items from the IS that parents endorsed as their child's current interest. See Table 2 for means and standard deviations for each group. Comparing the total number of items endorsed as an interest in each category revealed significant differences between groups for folk physics, $t(98)=-2.1, p<.05$, with children in the ASD group showing more folk physics interests than children with TD. In addition, differences between groups approached significance for folk psychology, $t(98)=$ $1.96, p=.05$, with children in the TD group showing more folk psychology interests than children in the ASD group.

Parents also reported whether their child was interested in playing alone and in playing with peers. A comparison of groups revealed that both groups of children were interested in playing alone (76\% in the TD group, and $90 \%$ in the ASD group). This difference was only marginally statistically significant, $\chi^{2}(1, n=100)=3.5, p=.06$ which may reflect that many of the typically developing children enjoyed solitary activities such as video games. There were more striking group differences in the proportion of children interested in playing with peers (96\% of TD children, $44 \%$ of children with ASD). This group difference was statistically significant, $\chi^{2}(1, n=100)=32.2, p<.001$.

Functional impairment-Parents answered a series of questions about the impairment associated with their child's primary interest on the IS. Groups were compared on total scores, as well as each item. Figure 1 displays the pattern of responses for each group. Groups were compared to determine whether the ASD group showed higher ratings of impairment and less involvement of people for their primary interest. Results supported our hypotheses, with significant differences found for the total impairment and for six of seven items. Specifically, children with ASD showed higher frequency, a higher degree of interference with other activities, a higher degree of resistance when interrupted, higher amount of accommodation required, lower degree of flexibility with their interest, and lower interest in involving other people than children with TD, all $p s<.05$.

\section{Circumscribed interests of the ASD sample}

Content-In contrast to the IS, which asked parents about a wide range of interests their child might have, the IRB-CI asked parents to describe the nature of their child's specific CI if they reported any. A total of 57 parents of children with ASD completed the IRB-CI. Of those 57, only 3 parents responded that their child did not have circumscribed interests, leaving $54(95 \%)$ with at least one circumscribed interest. Forty children (70\%) had more 
than one circumscribed interest. The list of these interests was categorized using BaronCohen and Wheelwright's (1999) categorization system, including the following categories: physics, psychology/people, mathematics, biology, taxonomy, attachments, facts, television, and sensory. Two independent raters completed the categorization, and allowed for an interest to be placed into more than one category. For example, a circumscribed interest of 'watching washing machines spin' was categorized as both folk physics, because it is an interest in mechanical functions, and sensory, because it involves staring at motion. Overall agreement was 87 per cent, and disagreements were discussed between the two raters and a consensus categorization was determined. See Table 3 for a list of representative CI in each category.

In addition, children's circumscribed interests were rated as 'typical' or 'unusual' by raters. Two independent raters also completed these categorizations, and agreed on $94 \%$ of ratings. Ratings of typical versus unusual interests were made based upon lists of primary interests given by parents of typical children. For example, an interest in video games, television shows, or a particular stuffed animal was rated as typical unless additional details made them unusual. One child was described as having an interest in a typical cartoon show. However, his mother also described how he frequently responded to questions in the voice of characters from that show; therefore, this interest was rated as unusual. Seventy per cent of children with ASD had at least one circumscribed interest that was rated as 'unusual' in content.

Impairment by content interaction-Within the ASD group, parents were asked questions about the functional impairment of their child's circumscribed interest in several areas on the IRB-CI: frequency of activity, intensity of interest, interference with other activities, and accommodation required by parents. To determine whether there was an interaction between content of interest and the level of impairment associated with that interest, the ASD group was first split into subgroups based upon whether they had any circumscribed interest rated as unusual or typical. Each impairment rating was compared across these groups (see Table 4). Results revealed statistically significant differences between groups for items measuring the intensity of the CI, $t(52)=2.0, p<.05$, and the interference with other activities, $t(52)=2.7, p<.01$, with children who manifested unusual interests showing higher levels of intensity and interference. No significant differences were found for the frequency of the activity or accommodations required by parents. A total impairment score was also computed across all items. The impairment score ranged from 0 (for children with no circumscribed interest) to 15, with higher scores reflecting higher frequency, intensity, interference and accommodation needed. The average impairment score for children with interests rated as typical was 4.3 (s.d. $=2.2)$ while the average impairment rating for children with unusual interests was 6.3 (s.d. $=2.9$ ). The difference between these two ratings was statistically signi-ficant, $t(52)=2.5, p<.05$, with higher impairment ratings associated with unusual interests.

Ratings of other autism symptoms for children with typical CI versus those with unusual CI were compared to determine whether the unusual nature of a child's CI was associated with overall severity of autism symptoms and cognitive impairment. Using the ADI-R domain scores as measures of symptom severity, groups with typical versus unusual interests were compared using $t$ tests (see Table 4). Results revealed no significant differences between groups for social or communication scores on the ADI-R, $p \mathrm{~s}>.3$, and differences in ADI-R repetitive behavior approached significance, (52) $t=1.8, p=.08$, reflecting that children with unusual $\mathrm{CI}$ had more impaired scores on the repetitive behavior domain of the ADI-R than children with typical CI. Differences in IQ were not significant $t(52)=1.6, p=.10$. 
Association of $\mathrm{Cl}$ to participant characteristics-Scores from both the IS and the IRB-CI were correlated with existing measures of autism symptoms in the ASD group. The total number of interests and total impairment rating from the IS as well as the total impairment rating from the IRB-CI were first correlated with the ADI-R repetitive behavior total score. Results revealed a significant correlation for the IS total number of interests, $\mathrm{r}(60)=.32, p<.05$, indicating that children with fewer total number of interests have higher, or more impaired, scores on the ADI-R repetitive behavior domain. Impairment ratings for the IS and IRB-CI were not signi-ficantly correlated with the ADI-R repetitive behavior score, $p s>.2$.

Total impairment scores for each measure and the total number of interests variable from the IS were also correlated with the ADI-R social and communication behavior ratings. Results revealed minimal association between these two measures and ADI-R social and communication scores, all $p s>.2$.

\section{Discussion}

The circumscribed interests of children with ASD are less studied and understood than other core symptom areas. However, a growing body of research has begun to support the notion that this aspect of repetitive behavior may be important to understanding the autism spectrum, and that it may be associated with unique pathogenic factors (Lam et al., 2008; Smith et al., 2009). The distinction between everyday interests and circumscribed interests also remains unclear. The present study examined in detail the amount, content, and intensity of interests in both children with ASD and those with typical development. Results indicated that the number of everyday interests children with ASD have does not differ from that of their typically developing peers. However, the nature and content of their interests is qualitatively different, and the degree of functional impairment associated with their interests is significantly greater in children with ASD. Results also supported the high prevalence of $\mathrm{CI}$ in the HFA population.

Parents of both typically developing children and children with ASD endorsed, on average, about 12 interests. The lack of difference between groups suggests that children with ASD are not necessarily restricted in the number of activities or topics they find interesting, but they appear to be drawn to different types of interests than their peers. While TD children tend to prefer activities that relate to social aspects of the world, children with ASD tend to prefer topics involving nonsocial and especially mechanical aspects of their environment. This finding replicates previous research conducted by Baron-Cohen and Wheelwright (1999).

Within the ASD sample, 95 per cent of parents indicated that their child had at least one circumscribed interest, and 70 per cent had more than one circumscribed interest. These rates are somewhat higher than previous estimates and may reflect the high-functioning nature of the sample. However, it is possible that previous research has undersampled CI, given the lack of specific measures for this aspect of autism symptomatology. Seventy per cent of children with ASD in this study had at least one circumscribed interest that was rated as 'unusual,' and the degree of impairment associated with these unusual interests was rated higher than that of children with circumscribed interests that were more typical in nature.

While there were no differences between groups in the strength of their primary interest, there were significant differences in the metrics of frequency, interference, flexibility, accommodation required by parents, and the degree to which children involve others in their interest. For all of these items, parents of children with ASD reported more challenges, indicating significantly higher levels of functional impairment associated with interests. 
These data support the idea that CI can be impairing for many children and may therefore be a viable target for treatment in some cases.

Despite indicators of potential functional impairment associated with CI, parents and clinicians sometimes debate whether or not to make CI or other repetitive behaviors the target for intervention. Some parents are struck by how 'proficient' their child is in the area of their CI (e.g. memorizing an impressive number of facts, precocious skills on the computer) and how this stands in contrast with all the other things their child is not able to do (e.g. socializing with peers, communicating clearly, adapting to school, et cetera). In these situations parents sometimes express a fear to tread on these 'islands of ability' (Mercier et al., 2000). However, another common scenario concerns parents who have seen the 'meltdowns' and negative effects on their child's behavior that can occur when the child is prevented from engaging in their repetitive behaviors or CI (Gabriels et al., 2005; Mercier et al., 2000). This appears to be a function of underlying behavioral rigidity or lack of flexibility whereby situations that involve lack of or limited access to interests can trigger bouts of severe irritability, aggression, self-injury or other problem behaviors (Green et al., 2006; Peters-Scheffer et al., 2008). From a clinical perspective, in at least a subset of cases the generalized rigidity and inflexibility associated with $\mathrm{CI}$ has the potential to interfere with learning and socialization, and may become a potential driver for mood and behavior problems. Further, the presence and severity of repetitive behaviors during early childhood appears to uniquely predict the overall severity of autism later in adolescence (Lord et al., 2006). Thus repetitive interests and behaviors have the potential for interfering with experience-dependent brain and behavioral development and family well-being, and treatment can be seen as a reasonable goal when viewed as an approach to expand the child's behavioral repertoire rather than simply thwarting or punishing the child's repetitive interests and behaviors.

Assuming that functionally impairing $\mathrm{CI}$ and associated mood and behavior problems may require intervention in at least a subset of cases, the question becomes: what form of intervention is likely to be effective? Recent controlled trials of joint attention and symbolic play interventions have demonstrated that these types of focused interventions can significantly impact core autism deficits in the area of social communication (Kasari et al., 2006; Schertz and Odom, 2007). To date, a similar approach has not been applied to the development of focused interventions for $\mathrm{CI}$ or other specific forms of repetitive behaviors in autism. A recent multisite randomized controlled trial of the serotonin reuptake inhibitor Citalopram for the treatment of repetitive behaviors in autism failed to find significant treatment effects (King et al., 2009), and thus presently there are no clear evidence-based pharmacotherapies indicated for the treatment of repetitive behaviors in autism. There is evidence that early behavioral treatment is an effective treatment for autism (Bristol, 1996; Dawson, 2008). However studies in this area have focused primarily on treating the socialcommunicative symptoms of autism. Indeed, a recent landmark study of the Early Start Denver Model (ESDM) for the treatment of toddlers with autism found clear, significant treatment-related improvements for a large variety of clinical outcomes (e.g. IQ, adaptive behavior, language, and socialization), however the comprehensive ESDM treatment package failed to impact repetitive behaviors (Dawson et al., 2010). To date, no studies have directly addressed a specific modification of early intensive behavioral intervention designed to treat repetitive behaviors in autism, and no forms of focused intervention in autism has been specifically developed to treat potentially impairing interests, preoccupations, and attachments exhibited in autism. One recent study has shown promise for a family implemented treatment of a variety of repetitive behaviors in young children (Boyd et al., 2010), but additional treatment development research for this domain of autistic impairment appears warranted. 
Similar to previous research (Lam et al., 2008), the present study did not find that impairments associated with CI were significantly associated with other features of ASD, or with IQ. These findings offer further support for the notion that CI reflect a unique feature of autism. Within the restricted and repetitive behavior domain of autism, there is clear overlap with other disorders for some features (American Psychiatric Association, 2000); for example, individuals with ASDs and intellectual disabilities display stereotyped movements (Bodfish et al., 2000), and individuals with ASDs, obsessive-compulsive disorder (OCD), and Tourette's disorder display ritualistic behavior (American Psychiatric Association, 2000). CI may be a symptom that is relatively more specific to ASDs than these other subtypes of restricted and repetitive behavior. If so, then sorting cases based on the presence/absence of CI may be a useful strategy for identifying a relatively homogenous subtype of ASD with respect to repetitive behavior.

CI present in idiosyncratic ways across cases, but all seem to involve a heightened interest in and restricted activity with circumscribed nonsocial aspects of the environment and experience. Clinically, CI seem to be associated with strong positive affect and anticipatory motivation, in contrast to repetitive behavior in other disorders such as OCD which seem to be associated with negative affect and anxiety-reduction (e.g. rituals, compulsions, insistence on sameness). Thus, features which are traditionally grouped together as 'repetitive behavior' may have important differences in terms of underlying neuropsychology and neural circuitry. If this is the case, then the elucidation of these distinct psychological and neurological properties may in turn inform future research on etiologic and treatment factors in autism. The heightened interest and restricted focus that is characteristic of CI suggest that cognitive-affective processes that mediate reward may be altered in persons with autism. In line with this, we hypothesize that the development of CI in ASD is mediated by an underlying cognitive-affective reward system that is 'biased' away from social information and towards nonsocial information (Sasson et al., 2008). Initial functional magnetic resonance imaging studies by our research group suggest altered functioning of brain reward networks in autism while processing stimuli representing CI as well as to other classes of rewarding stimuli (Dichter, Felder, et al, in press; Dichter, Richey, et al, in press). Although reward processes and their underlying neural circuitry are novel areas of inquiry in autism, an advantage of research in this area is that considerable advances on valid paradigms, associated neural circuitry, and even animal models, gene candidates, and focused treatments already exists from work on other neuropsychiatric disorders (e.g. affective disorders, addictive disorders).

The weaknesses of this study should be noted. First, this study utilized only parental report of CI symptoms, and future research that includes observational and self-report measures of CI could be informative. Second, comparisons were made between children with ASD and typical development only, without comparison between the ASD group and a clinical comparison group. This type of comparison will be essential to further examine the specificity of CI to ASDs. Finally, only high-functioning individuals with ASD participated, making it more challenging to draw conclusions about the entire population of individuals with ASD.

Future research should further examine the unique nature of CI in ASD relative to other groups, and examine this construct more thoroughly across the age span, including examination of the early development of CI. Future research will also examine more closely the most efficient way to measure these constructs through additional statistical analysis of our measures and further development of observational measures of CI. Given that parents of children with autism reported significantly more functional impairment stemming from CI than parents of typically developing children, more work involving the utility and feasibility of treatments targeting these behaviors seems to be warranted. 


\section{Acknowledgments}

This research was supported by NIH grant R01 MH073402 (Bodfish). L.M. Turner-Brown, G. Dichter, and K.S.L. Lam were supported by NICHD T32-HD40127. L.M. Turner-Brown was also supported by NC Division TEACCH. G. Dichter was supported by NIH/NCRR K12 RR023248 and NIMH K23 MH081285. Assistance for this study was provided by the Subject Registry Core of the UNC Neurodevelopmental Disorders Research Center (P30 HD03110). Tia Holtzclaw is now at the University of Alabama in the Department of Psychology. The Interests Scale and Interview for Repetitive Behavior are available upon request from the authors.

\section{References}

American Psychiatric Association. Diagnostic and Statistical Manual of Mental Disorders. 4. Washington, DC: APA; 2000. text revision

Baron-Cohen S, Wheelwright S. "Obsessions” in Children with Autism or Asperger Syndrome. Content Analysis in Terms of Core Domains of Cognition. British Journal of Psychiatry. 1999; 175:484-490. [PubMed: 10789283]

Bartak L, Rutter M. Differences between Mentally Retarded and Normally Intelligent Autistic Children. Journal of Autism and Childhood Schizophrenia. 1976; 6:109-120. [PubMed: 989485]

Bodfish, JW. Interests Scale. Chapel Hill, NC: 2003.

Bodfish JW, Symons FJ, Parker DE, Lewis MH. Varieties of Repetitive Behavior in Autism: Comparisons to Mental Retardation. Journal of Autism and Developmental Disorders. 2000; 30(3): 237-243. [PubMed: 11055459]

Bodfish, JW.; Symons, FW.; Lewis, MH. The Repetitive Behavior Scale. Western Carolina Center Research Reports; 1999.

Boyd BA, McDonough SG, Rupp B, Khan F, Bodfish JW. Effects of a Family-Implemented Treatment on the Repetitive Behaviors of Children with Autism. Journal of Autism and Developmental Disorders. (in press).

Bristol MM, Cohen DJ, Costello EJ, Denckla M, Eckberg, et al. State of the Science in Autism: Report to the National Institutes of Health. Journal of Autism and Developmental Disorders. 1996; 26(2): 121-157. [PubMed: 8744475]

Constantino, JN.; Gruber, CP. SRS Manual. Los Angeles: Western Psychological Services; 2002. Social Responsiveness Scale (SRS).

Cuccaro ML, Shao Y, Grubber J, Slifer M, Wolpert CM, et al. Factor Analysis of Restricted and Repetitive Behaviors in Autism Using the Autism Diagnostic Interview-Revised. Child Psychiatry and Human Development. 2003; 34(1):3-17. [PubMed: 14518620]

Dawson G. Early Behavioral Intervention, Brain Plasticity, and the Prevention of Autism Spectrum Disorder. Developmental Psychopathology. 2008; 20(3):775-803.

Dawson G, Rogers S, Munson J, Smith M, Winter J, et al. Randomized, Controlled Trial of an Intervention for Toddlers with Autism:The Early Start Denver Model. Pediatrics. 2010; 125(1):e17-23. [PubMed: 19948568]

DeLoache JS, Simcock G, Macari S. Planes, Trains, Automobiles - and Tea Sets: Extremely Intense Interests in Very Young Children. Developmental Psychology. 2007; 43(6):1579-1586. [PubMed: 18020834]

Dichter GS, Felder JN, Green SR, Rittenberg AM, Sasson NJ, Bodfish JW. Reward Circuitry Function in Autism Spectrum Disorders. Social, Cognitive, and Affective Neuroscience. (in press).

Freeman BJ, Ritvo ER, Schroth PC, Tonick I, Guthrie D, Wake L. Behavioral Characteristics of Highand Low-IQ Autistic Children. American Journal of Psychiatry. 1981; 138(1):25-29. [PubMed: 7446777]

Gabriels RL, Cuccaro ML, Hill DE, Ivers BJ, Goldson E. Repetitive Behaviors in Autism: Relationships with Associated Clinical Features. Research in Developmental Disabilities. 2005; 26(2):169-181. [PubMed: 15590247]

Green VA, Sigafoos J, Pituch KA, Itchon J, O’Reilly M, Lancioni GE. Assessing Behavioral Flexibility in Individuals with Developmental Disabilities. Focus on Autism and Other Developmental Disabilities. 2006; 21(4):230-236. 
Kanner L. Autistic Disturbances of Affective Contact. The Nervous Child: Quarterly Journal of Psychopathology, Psychotherapy, Mental Hygiene, and Guidance of the Child. 1943; 2:217-250.

Kasari C, Freeman S, Paparella T. Joint Attention and Symbolic Play in Young Children with Autism: A Randomized Controlled Intervention Study. Journal of Child Psychology and Psychiatry. 2006; 47(6):611-620. [PubMed: 16712638]

King BH, Hollander E, Sikich L, McCracken JT, Scahill L, et al. Lack of Efficacy of Citalopram in Children with Autism Spectrum Disorders and High Levels of Repetitive Behavior: Citalopram Ineffective in Children with Autism. Archives of General Psychiatry. 2009; 66(6):583-590. [PubMed: 19487623]

Koegel RL, Covert A. The Relationship of Self-Stimulation to Learning in Autistic Children. Journal of Applied Behavioral Analysis. 1972; 5(4):381-387.

Koegel RL, Firestone PB, Kramme KW, Dunlap G. Increasing Spontaneous Play by Suppressing SelfStimulation in Autistic Children. Journal of Applied Behavioral Analysis. 1974; 7(4):521-528.

Lam KS, Aman MG. The Repetitive Behavior Scale-Revised: Independent Validation in Individuals with Autism Spectrum Disorders. Journal of Autism \& Developmental Disorders. 2007; 37(5): 855-866. [PubMed: 17048092]

Lam, KS.; Aman, MG.; Parker, D.; Woodard, C.; Lewis, MH.; Bodfish, JW. Psychometric Properties of the Repetitive Behavior Scale-Revised (RBS-R) in Children and Adults with Autism Spectrum Disorders. Paper presented at the CPEA/STAART Conference; Bethesda, MD. 2005.

Lam KS, Bodfish JW, Piven J. Evidence for Three Subtypes of Repetitive Behavior in Autism that Differ in Familiality and Association with Other Symptoms. Journal of Child Psychology and Psychiatry. 2008; 49(11):1193-1200. [PubMed: 19017031]

Lewis MH, Bodfish JW. Repetitive Behavior Disorders in Autism. Mental Retardation and Developmental Disabilities Research Reviews. 1998; 4(2):80-89.

Lord C, Risi S, DiLavore PS, Shulman C, Thurm A, Pickles A. Autism from 2 to 9 Years of Age. Archives of General Psychiatry. 2006; 63(6):694-701. [PubMed: 16754843]

Lord C, Rutter M, Le Couteur A. Autism Diagnostic Interview-Revised: A Revised Version of a Diagnostic Interview for Caregivers of Individuals with Possible Pervasive Developmental Disorders. Journal of Autism \& Developmental Disorders. 1994; 24(5):659-685. [PubMed: 7814313]

Lovaas OI, Schreibman L, Koegel R, Rehm R. Selective Responding by Autistic Children to Multiple Sensory Input. Journal of Abnormal Psychology. 1971; 77(3):211-222. [PubMed: 5556929]

Mercier C, Mottron L, Belleville S. A Psychosocial Study on Restricted Interests in High-Functioning Persons with Pervasive Developmental Disorders. Autism. 2000; 4(4):406-425.

Ozonoff S, South M, Miller JN. DSM-IV-defined Asperger syndrome: Cognitive, Behavioral and Early History Differentiation from High-Functioning Autism. Autism. 2000; 4(1):29-46.

Peters-Scheffer N, Didden R, Green VA, Sigafoos J, Korzilius H, et al. The Behavior Flexibility Rating Scale-Revised (BFRS-R): Factor Analysis, Internal Consistency, Inter-Rater and IntraRater Reliability, and Convergent Validity. Research in Developmental Disabilities. 2008; 29(5): 398-407. [PubMed: 17826945]

Pierce K, Courchesne E. Evidence for a Cerebellar Role in Reduced Exploration and Stereotyped Behavior in Autism. Biological Psychiatry. 2001; 49(8):655-664. [PubMed: 11313033]

Roid, GH.; Miller, LJ. Leiter International Performance Scale - Revised. Wood Dale, IL: Stoelting; 2002.

Sasson NJ, Turner-Brown LM, Holtzclaw TN, Lam KS, Bodfish JW. Children with Autism Demonstrate Circumscribed Attention during Passive Viewing of Complex Social and Nonsocial Picture Arrays. Autism Research. 2008; 1(1):31-42. [PubMed: 19360648]

Schertz HH, Odom SL. Promoting Joint Attention in Toddlers with Autism: A Parent-Mediated Developmental Model. Journal of Autism \& Developmental Disorders. 2007; 37(8):1562-1575. [PubMed: 17096190]

Smith CJ, Lang CM, Kryzak L, Reichenberg A, Hollander E, Silverman JM. Familial Associations of Intense Preoccupations, an Empirical Factor of the Restricted, Repetitive Behaviors and Interests Domain of Autism. Journal of Child Psychology and Psychiatry. 2009; 50(8):982-90. [PubMed: 19298470] 
South M, Ozonoff S, McMahon WM. Repetitive Behavior Profiles in Asperger Syndrome and HighFunctioning Autism. Journal of Autism \& Developmental Disorders. 2005; 35(2):145-158. [PubMed: 15909401]

Turner M. Annotation: Repetitive Behaviour in Autism: A Review of Psychological Research. Journal of Child Psychology and Psychiatry. 1999; 40(6):839-849. [PubMed: 10509879]

Varni JW, Lovaas OI, Koegel RL, Everett NL. An Analysis of Observational Learning in Autistic and Normal Children. Journal of Abnormal Child Psychology. 1979; 7(1):31-43. [PubMed: 438430] 


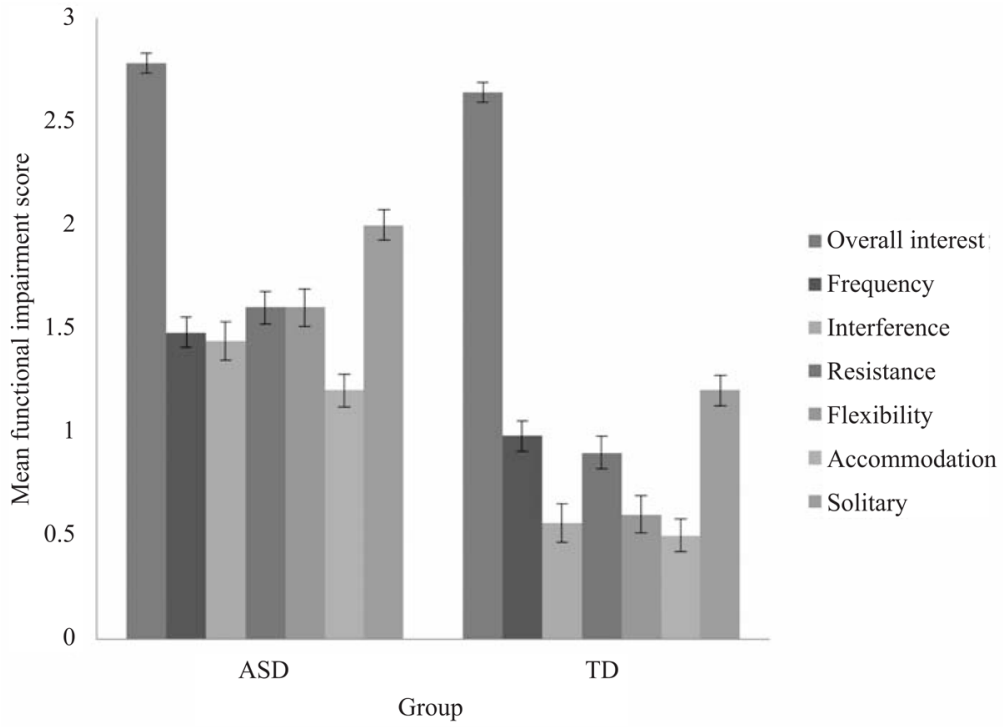

Figure 1.

Functional impairment ratings of primary interests for typically developing (TD) and autism spectrum disorder (ASD) groups 
Table 1

Demographic characteristics of total sample and matched sample

\begin{tabular}{|c|c|c|c|c|}
\hline & \multicolumn{2}{|c|}{ Total sample } & \multicolumn{2}{|c|}{ Matched sample } \\
\hline & ASD group $(n=60)$ & TD group $(n=63)$ & ASD group $(n=50)$ & TD group $(n=50)$ \\
\hline \multicolumn{5}{|l|}{ Age in months } \\
\hline Mean (s.d.) & $125.2(35.0)$ & $140.3(40.0)$ & $127.0(33.3)$ & $138.2(38.2)$ \\
\hline Range & $74-207$ & $75-214$ & $75-207$ & 75-206 \\
\hline \multicolumn{5}{|l|}{ Leiter-R Brief IQ } \\
\hline Mean (s.d.) & $99.7(16.1)$ & $111.4(15.9)$ & $102.0(15.7)$ & 106.5 (13.6) \\
\hline Range & $73-139$ & $74-145$ & $73-139$ & $74-133$ \\
\hline Gender ( $\%$ male) & $95 \%$ & $94 \%$ & $96 \%$ & $92 \%$ \\
\hline Ethnicity (\% Caucasian) & $81 \%$ & $76 \%$ & $80 \%$ & $70 \%$ \\
\hline
\end{tabular}

Note. $\mathrm{ASD}=$ autism spectrum disorder; $\mathrm{TD}=$ typically developing. 
Table 2

Mean (and SD) scores from the Interest Scale for the ASD and TD groups

\begin{tabular}{|c|c|c|}
\hline Variable & ASD group $(n=50)$ & TD group $(n=50)$ \\
\hline \multicolumn{3}{|l|}{ Number and content } \\
\hline Number of current interests & $12.3(6.4)$ & $12.4(6.1)$ \\
\hline N. Folk Physics interests & $2.7(2.4)^{*}$ & $1.9(1.6)$ \\
\hline N. Folk Psychology interests & $0.3(0.5)$ & $0.5(0.7)$ \\
\hline$\%$ interested in social games & $44 \%{ }^{*}$ & $96 \%$ \\
\hline$\%$ interested in playing alone & $90 \%$ & $76 \%$ \\
\hline \multicolumn{3}{|l|}{ Impairment ratings } \\
\hline Overall interest (1-3) & $2.8(0.5)$ & $2.6(0.5)$ \\
\hline Frequency of activity (0-3) & $1.5(0.8)^{*}$ & $1.0(0.6)$ \\
\hline Degree of interference $(0-3)$ & $1.4(1.0)^{*}$ & $0.6(0.6)$ \\
\hline Degree of resistance $(0-3)$ & $1.6(0.8)^{*}$ & $0.9(0.6)$ \\
\hline Degree of flexibility $(0-3)$ & $1.6(0.9)^{*}$ & $0.6(0.7)$ \\
\hline Accommodation required $(0-3)$ & $1.2(0.8)^{*}$ & $0.5(0.6)$ \\
\hline Involvement of people (0-3) & $2.0(0.6)^{*}$ & $1.2(0.7)$ \\
\hline Total intensity rating & $12.1(3.3)^{*}$ & $7.4(2.3)$ \\
\hline
\end{tabular}

${ }^{*} p<.05$.

Note. $\mathrm{ASD}=$ autism spectrum disorder; $\mathrm{TD}=$ typically developing. 
Table 3

The Interview for Repetitive Behavior: Circumscribed Interests in the ASD sample $(n=57)$

\begin{tabular}{|c|c|c|}
\hline Category & Percentage of children & Examples of circumscribed interests \\
\hline Physics & $56 \%(n=30)$ & $\begin{array}{l}\text { Cranes/mechanical function } \\
\text { Preoccupied with trains } \\
\text { Legos }\end{array}$ \\
\hline Attachments & $48 \%(n=26)$ & $\begin{array}{l}\text { Carries a piece of cloth with him everywhere } \\
\text { Attached to stuffed dog } \\
\text { Jewelry - upset when taken off }\end{array}$ \\
\hline Taxonomy (primarily collecting) & $33 \%(n=18)$ & $\begin{array}{l}\text { Pokemon card collecting } \\
\text { Interest in dinosaurs - collects them } \\
\text { Collects rocks }\end{array}$ \\
\hline Television & $30 \%(n=16)$ & $\begin{array}{l}\text { Cartoon network } \\
\text { Star Wars movies } \\
\text { Sponge Bob }\end{array}$ \\
\hline Biology & $17 \%(n=9)$ & $\begin{array}{l}\text { Birds of prey } \\
\text { Evolution/dinosaurs } \\
\text { Cougars }\end{array}$ \\
\hline Facts & $13 \%(n=7)$ & $\begin{array}{l}\text { Prints Wikipedia articles about videogame characters } \\
\text { Details about actors/directors of movies } \\
\text { Confederate wars }\end{array}$ \\
\hline Mathematics & $11 \%(n=6)$ & $\begin{array}{l}\text { N. } 22 \text { is his number; } 22 \text { nd day of month is his day } \\
\text { Interest in dates. } \\
\text { Numbers - clocks, calendars, exit numbers } \\
\text { Reads math theory books }\end{array}$ \\
\hline Sensory & $8 \%(n=4)$ & $\begin{array}{l}\text { Stares at anything in motion } \\
\text { Fascination with running water for hours } \\
\text { Watches washing machine spin }\end{array}$ \\
\hline Psychology/People & $6 \%(n=3)$ & $\begin{array}{l}\text { Fashion and make-up } \\
\text { Pokemon club at recess } \\
\text { Imaginary friends }\end{array}$ \\
\hline
\end{tabular}


Table 4

Mean (and SD) of CI impairment scores, ASD severity scores, and IQ scores for ASD subgroup with unusual interests and ASD subgroup with typical interests

\begin{tabular}{lcc}
\hline & Unusual interests $(\boldsymbol{n}=\mathbf{3 9})$ & Typical interests $(\boldsymbol{n}=\mathbf{1 5})$ \\
\hline IRB-CI: frequency (0-5) & $2.4(1.5)$ & $1.9(0.9)$ \\
IRB-CI: intensity (0-4) & $2.0(1.2)^{*}$ & $1.3(1.1)$ \\
IRB-CI: interference (0-3) & $1.3(0.9)^{*}$ & $0.6(0.8)$ \\
IRB-CI: accommodation (0-3) & $0.6(0.9)$ & $0.5(0.7)$ \\
IRB-CI TOTAL impairment rating (0-15) & $6.4(2.9)^{*}$ & $4.3(2.1)$ \\
ADI-R Social & $19.6(4.9)$ & $18.1(4.9)$ \\
ADI-R Communication & $15.0(4.5)$ & $15.1(3.2)$ \\
ADI-R RRB & $7.5(2.4)$ & $6.2(2.2)$ \\
Leiter Brief IQ & $97.8(16.5)$ & $106.1(16.9)$ \\
\hline
\end{tabular}

* $p<.05$.

Note. $\mathrm{CI}$ = circumscribed interests; ASD = autism spectrum disorder; IRB = Interview for Repetitive Behaviors; ADI-R = Autism Diagnostic Interview-Revised; RRB = restricted and repetitive behavior. 